\title{
Effects of erythropoietin on methotrexate induced lung injury in rats
}

\author{
Hasan Kahraman ${ }^{1 \star}$, Vedat Bakan², Ergul Kurutas ${ }^{3}$, Mahmut Tokur ${ }^{4}$, Nurhan Koksal ${ }^{1}$ and \\ Harun Cıralik ${ }^{5}$
}

\begin{abstract}
${ }^{1}$ Chest Disease, Faculty of Medicine, Kahramanmaras Sutcuimam University, Kahramanmaras, Turkey. ${ }^{2}$ Pediatric Surgery, Faculty of Medicine, Kahramanmaras Sutcuimam University, Kahramanmaras, Turkey. ${ }^{3}$ Biochemistry, Faculty of Medicine, Kahramanmaras Sutcuimam University, Kahramanmaras, Turkey. ${ }^{4}$ Chest Surgery, Faculty of Medicine, Kahramanmaras Sutcuimam University, Kahramanmaras, Turkey.

${ }^{5}$ Pathology, Faculty of Medicine, Kahramanmaras Sutcuimam University, Kahramanmaras, Turkey.
\end{abstract}

Accepted 5 November, 2012

\begin{abstract}
The aim of our study was to investigate the effect of erythropoietin on methotrexate induced lung injury in rats. Twenty-one female Sprague-Dawley rats were randomly assigned into 3 groups $(n=7)$. Singledose subcutaneous injections of $0.3 \mathrm{ml}$ serum physiologic was administered to sham group, singledose $20 \mathrm{mg} / \mathrm{kg}$ methotrexate was administered to the control group, and single-dose $20 \mathrm{mg} / \mathrm{kg}$ methotrexate and $5000 \mathrm{IU} / \mathrm{kg}$ erythropoietin to different areas were administered to the study group. On the 5th day, rats were sacrificed and the right lungs were biochemically and histopathologically evaluated. We determined the malondialdehyde levels which were significantly lower in sham group than those in the control and study groups (both $P=0.002$ ) and in the study group, the levels were lower than in the control group, but not statistically significant. Inflammation and congestion scores in the control group were significantly higher than those in the sham group ( $P=0.02$ and $P=0.01$, respectively). In the study group, scores were lower but not significant than those in the control group. Although, levels of antioxidant and scores were decreased, we could not determine statistically significant protective effects of erythropoietin at dose of $5000 \mathrm{IU} / \mathrm{kg}$, on methotrexate induced lung injury of rat.
\end{abstract}

Key words: Methotrexate, erythropoietin, antioxidant, lung injury.

\section{INTRODUCTION}

Drugs such as methotrexate (MTX), bleomycin, and amiodarone have been known to be related with development of pulmonary diseases (Ohbayashi et al., 2010). MTX, a folic acid antagonist, show its effects prominently in tissues with high mitotic rates, such as in malignant tumors, bone marrow, testis, gastrointestinal tract, and bladder mucosa (Bedrossian, 1988). Besides its antiproliferative effect, MTX also has an anti-inflammatory and immunomodulating effects (Cronstein, 1996; Goodman and Polisson, 1994). With high doses, it has

\footnotetext{
*Corresponding author. E-mail: drhasankahraman@hotmail.com.
} Tel: +90 5338164036. Fax: +90 3442212371 . been used for the treatment of different diseases and malignancies like leukemia, breast, head, neck, and lung carcinomas, and rheumatoid arthritis (Cooper et al., 1986). Sixty to ninety-three percentage of patients treated with MTX eventually develop adverse reactions and most of these reactions are not life-threatening, but up to $30 \%$ of patients treated with MTX for more than five years, eventually discontinue the MTX therapy, because of unacceptable toxicity (Goodman and Polisson, 1994). Pulmonary, hepatic, and hematologic side-effects are the major and potentially life-threatening toxicities (Salach and Cash, 1996). Studies generally suggest that pulmonary toxicities arise in 2 to $8 \%$ of patients receiving MTX, but others define as high as 33\% (Salach and Cash, 1996). The precise mechanisms of MTX-induced 
pulmonary injury are not known. Most researchers think that MTX generates a type IV delayed hypersensitivity pneumonitis presenting lymphocytic proliferation and alveolitis (Chikura et al., 2008; Cooper et al., 1986). Some side effects are thought to emerge from idiosyncratic mechanisms unrelated to folate antagonism, because pulmonary toxicities occur with both low and high doses and occur by different routes of administration (Ohbayashi et al., 2010).

Reactive oxygen species (ROS) are produced as a result of normal cellular metabolism (Ergur et al., 2008; Thannickal and Fanburg, 2000). ROS aroused from the partial reduction of oxygen, represent their cytotoxic effects by directly modifying cellular and extracellular components. It is well known that chemical-induced cellular injury can lead to oxidative stress, because of an imbalance between the generation of ROS and their detoxification in tissues. ROS-induced injury is well characterized and includes DNA base oxidation, lipid peroxidation, and protein oxidation (Laskin et al., 2010). Malondialdehyde (MDA) is a marker of oxidative stress and is formed during lipid peroxidation of tissue (Naziroglu, 2007).

Erythropoietin (EPO), a hypoxia-inducible hematopoietic growth factor, has antiapoptotic, antioxidant, anti-inflammatory, and angiogenic effects. In addition to its traditional hematopoietic role, recently, it is highlighted that EPO has cytoprotective effects (Jelkmann, 2007; Mori et al., 2008). Wu et al. (2006) demonstrated that pretreatment with EPO appears to attenuate ischemia-reperfusion-induced lung injury. In another study, EPO was shown to reduce oxidative stress-associated lipid peroxidation in lung tissue (Tascilar et al., 2007).

The role of ROS and the protective effect of EPO on MTX-induced lung injury have not been investigated yet. On the basis of the aforementioned findings, we conducted this study to examine biochemically and histopathologically the protective effects of EPO on MTX induced lung damage in a rat model.

\section{MATERIALS AND METHODS}

\section{Animals}

This study was approved by the Ethics Committee on Animal Research at the Faculty of Medicine of Kahramanmaraş Sütçü Imam University. For the study, 21 female Sprague-Dawley rats, weighing 210 to $230 \mathrm{~g}$ each were selected and acclimatized for 10 days in the animal laboratory of our university research center, receiving a standard diet and water ad libitum. The rats were divided into 3 groups: sham group (sham operation, $n=7$ ) animals were administered single-dose subcutaneous (SC) injections of 0.3 $\mathrm{ml}$ serum physiologic; control group animals (MTX group, $\mathrm{n}=7$ ) were administered single-dose SC injections of MTX $(20 \mathrm{mg} / \mathrm{kg})$; and study animals (EPO group, $\mathrm{n}=7$ ) were administered singledose SC injections of MTX (20 mg/kg) and EPO (5000 IU/ $/ \mathrm{kg}$, Recormon, Roche Diagnostics GmbH, Mannheim, Germany) separately. On the 5th day, animals in all groups were sacrificed by decapitation and the right lungs were removed. One halves of removed lungs were stored at $-80^{\circ} \mathrm{C}$ until biochemical analysis and the other halves were fixed in $10 \%$ neutral-buffered formaldehyde solution for histological evaluation (Ohbayashi et al., 2010; Rubio et al., 1998; Pesce et al., 1985).

\section{Biochemical evaluation}

Oxidative stress was evaluated by measuring the levels of MDA. Tissues were weighed and placed in $1.15 \%$ potassium chloride $(\mathrm{KCl})$ solution, then homogenized for $30 \mathrm{~min}$ at $14,000 \mathrm{rpm}$. The aliquots homogenate were centrifugated at $10,000 \mathrm{rpm}$ for $30 \mathrm{~min}$ and the supernatants were analyzed for MDA. The concentration of plasma lipid peroxidation (total MDA, expressed in nanomoles per mg protein) was measured by the Ohkawa method (Ohkawa et al., 1979).

\section{Histopathologic evaluation}

The samples were fixed in $10 \%$ neutral buffered formalin solution and embedded in paraffin. Serial sections were cut in $4 \mu \mathrm{m}$ thick slices, stained with hematoxylin-eosin, and examined by light microscopy for the presence of tissue damage. A single pathologist examined and scored the lung sections in a blinded fashion. Five microscopy fields were evaluated for the presence of tissue congestion and inflammation. For congestion scale was scored as 0 representing no pathologic findings and 1,2 , and 3 representing pathologic findings of less than 25\%, 25 to $75 \%$, and more than $75 \%$ of the fields, respectively. For inflammation or leukocytic infiltration scale was scored as follows: 0, no extravascular leukocytes; $1,<10$ leukocytes; 2, 10 to 45 leukocytes; 3, >45 leukocytes. An average of the numbers was used for comparison (Calikoglu et al., 2003).

\section{Statistical analysis}

Statistical analyses were carried out using the statistical package of SPSS 15.0 for Windows (SPSS, Inc., Chicago, IL, USA). Analysis of variance (ANOVA) was carried out on the biochemical data to examine differences among groups. When a significant group effect was found, Kruskal-Wallis followed by Mann-Whitney $U$ tests were performed. Statistical significance was defined as $\mathrm{P}<0.05$. Tissue damage scores were compared by nonparametric analysis, and statistical significance was determined by Kruskal-Wallis followed by Mann-Whitney $U$ test. The data were expressed as mean \pm standard deviation (SD).

\section{RESULTS}

\section{Biochemical}

MDA levels of the sham, MTX and EPO groups were measured. MDA levels of sham group was significantly lower than those of MTX and EPO groups (both $\mathrm{P}=$ 0.002). MDA level in the EPO group was lower than in the MTX group, but the difference was not significant statistically $(P>0.05)$ (Figure 1$)$.

\section{Histopathological}

Inflammation score (IS) and congestion score (CS) of sham, MTX and EPO groups were measured. The IS of 


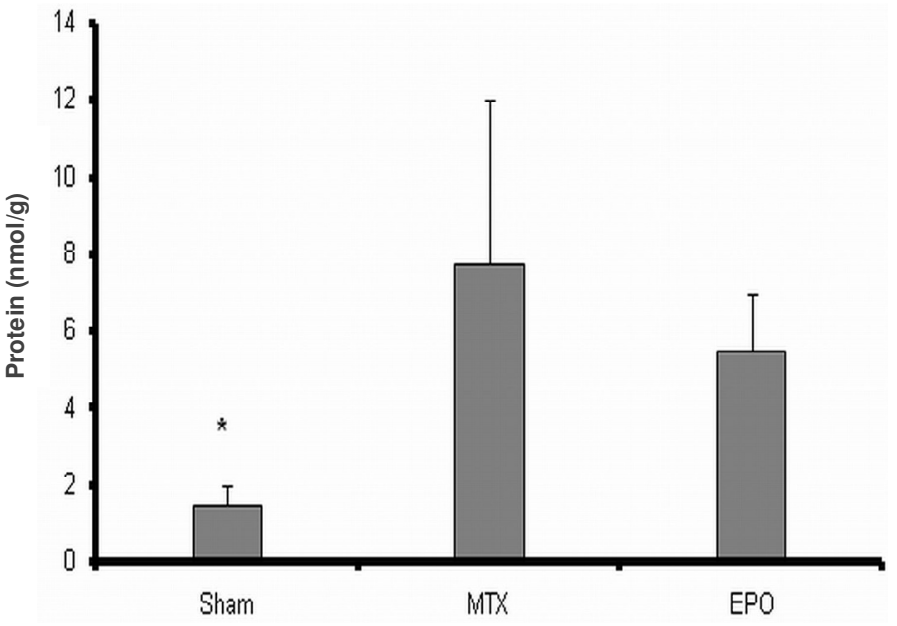

Figure 1. Malondialdehyde (MDA) levels in rat lung tissue. The groups were sham, MTX (one dose methotrexate), and EPO (methotrexate plus erythropoietin given) groups. *MDA level of sham was significantly lower than those of MTX and EPO groups $(\mathrm{P}<0.05)$.

the sham group was significantly lower than the MTX group $(P=0.02)$ (Figure 2). The IS of the EPO group was lower than the MTX group, but the decrease was not statistically significant $(P>0.05)$. Congestions and inflammations of rat lung are shown in Figures 3 and 4.

\section{DISCUSSION}

In this study, the $5^{\text {th }}$ day effects of one dose subcutaneous administration of MTX on the rat lung were evaluated early. The effects of $5000 \mathrm{IU} / \mathrm{kg}$ dose of EPO administration on MTX-induced lung injury were also investigated. Our biochemical results suggested that subcutaneous MTX administration increases the oxidative stress marker significantly and addition of exogenous EPO decreases the oxidative stress marker, but the observed effect did not reach statistically significant level. In MTX given group, pathological investigation of inter-alveolar septa showed higher lymphocytic inflammation and congestion scores than those in MTX plus EPO given group, but the difference was not significant. These results have similarities with previous experimental studies on other tissues (Dasgupta et al., 2011; Garipardic et al., 2010).

The most common pulmonary toxicity associated with the use of MTX is hypersensitivity pneumonitis. The other pulmonary conditions are bronchiolitis obliterans with organizing pneumonia (BOOP), acute lung injury with noncardiogenic pulmonary edema, pulmonary fibrosis, and bronchitis with airway hyperreactivity (Cooper et al., 1986; Cronstein, 1996). Most researchers think that MTX generates a type IV delayed hypersensitivity pneumonitis presenting lymphocytic proliferation and alveolitis

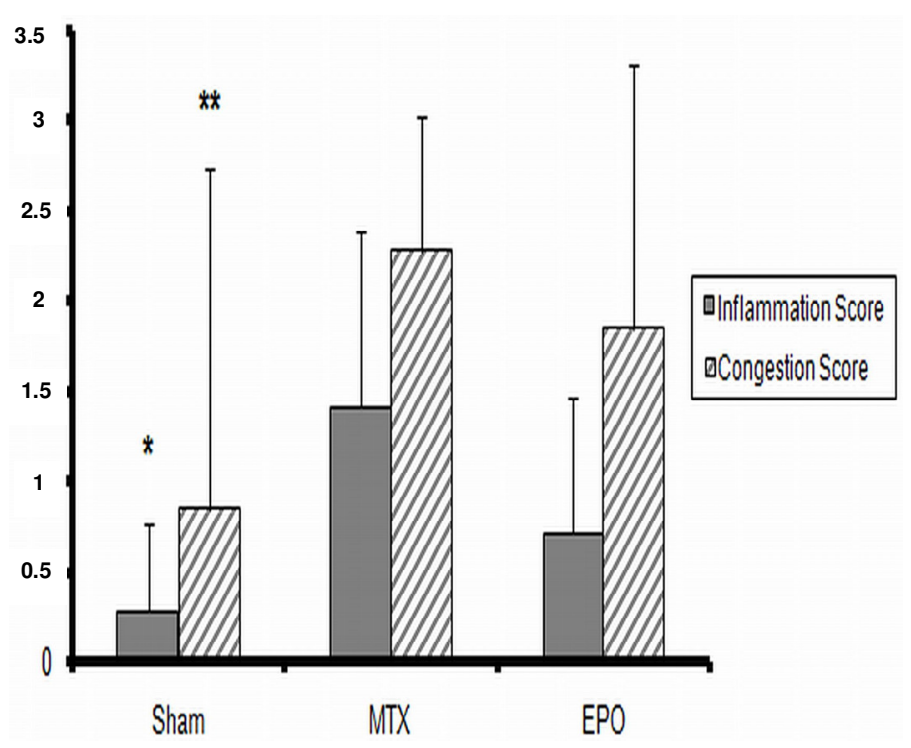

Figure 2. Inflammation and congestion scores of all three groups were shown; *Inflammation score of sham was significantly lower than those of MTX group $(P=0.02) ;{ }^{* \star}$ Congestion score of sham was significantly lower than those of MTX group $(P=0.01)$.

(Chikura et al., 2008; Cooper et al., 1986). In our study, we determined that MTX increases significantly lymphocytic inflammation and congestion in histopathological examination of rat lung. Our results support the thought that MTX generates a type IV delayed hypersensitivity pneumonitis.

In the last decade, researches have shown that EPO and its receptors are expressed in tissues other than those concerned in erythropoiesis. Non-erythropoietic functions of EPO are widespread and play a role in organogenesis during early embryonic development and have effects on recovery of tissues injured by ischemia, mechanical trauma, excitotoxins, and other stressors (Sasaki et al., 2001; Sepodes et al., 2006; Vogel and Gassmann, 2011). It has been shown that EPO prevents inflammation by preserving the cellular membrane asymmetry (Maiese et al., 2005). Also in humans EPO has potential cytoprotective effects on lung tissues (Tascilar et al., 2007; Wu et al., 2006; Yildirim et al., 2005). EPO has been demonstrated to decrease lipid peroxidation levels in hypoxic-ischemic brain injury(Kumral et al., 2005) and in MTX-induced esophageal damage (Garipardic et al., 2010). In one study, acute lung injury was induced by experimental acute pancreatitis and EPO was given to measure its effect. It is found that EPO reduced the MDA levels significantly and is determined to have cytoprotective effect (Tascilar et al., 2007). In the present study, MDA level in MTX group increased significantly than in sham group. In EPO group, MDA level was lower than those in MTX group, but the difference was not significant. So we cannot conclude that EPO has anti-inflammatory effects on lung tissue. 


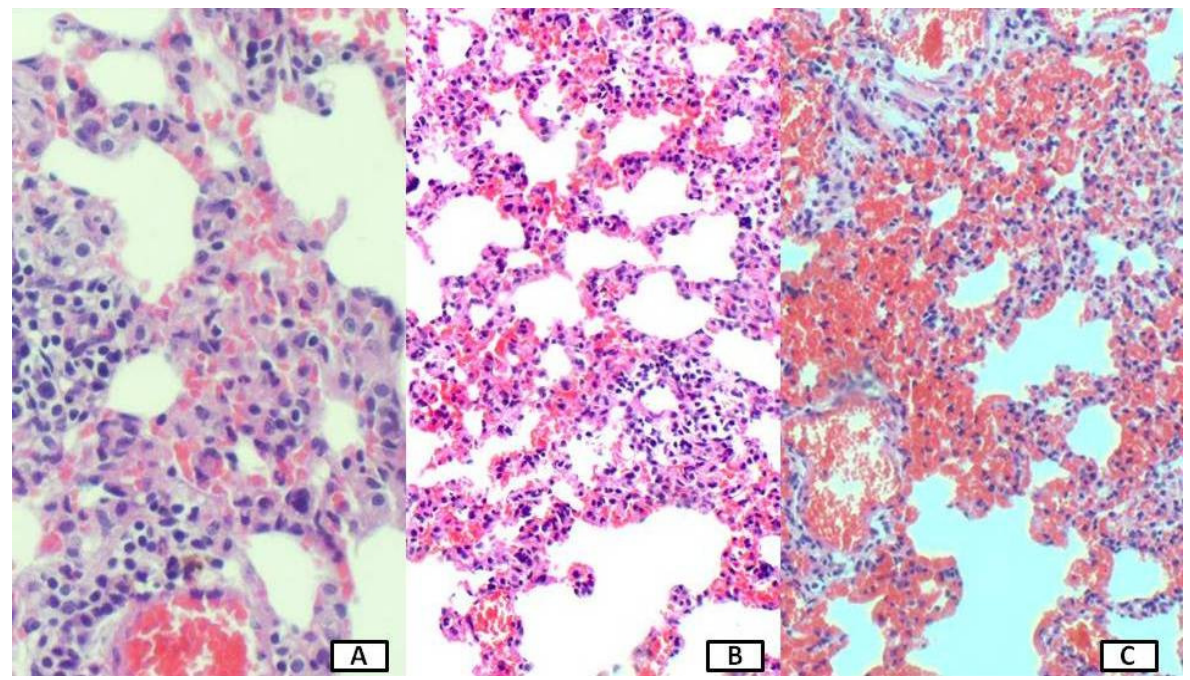

Figure 3. (A) Normal grade 0 tissue congestion, in a sham rat lung ( $H \& E, \times 200)$; (B) moderate congestion in the lung of erythropoietin plus methotrexate given rat $(\mathrm{H} \& \mathrm{E}$ $\times 100)$; (C) severe congestion in the lung of methotrexate given rat $(H \& E \times 100)$.

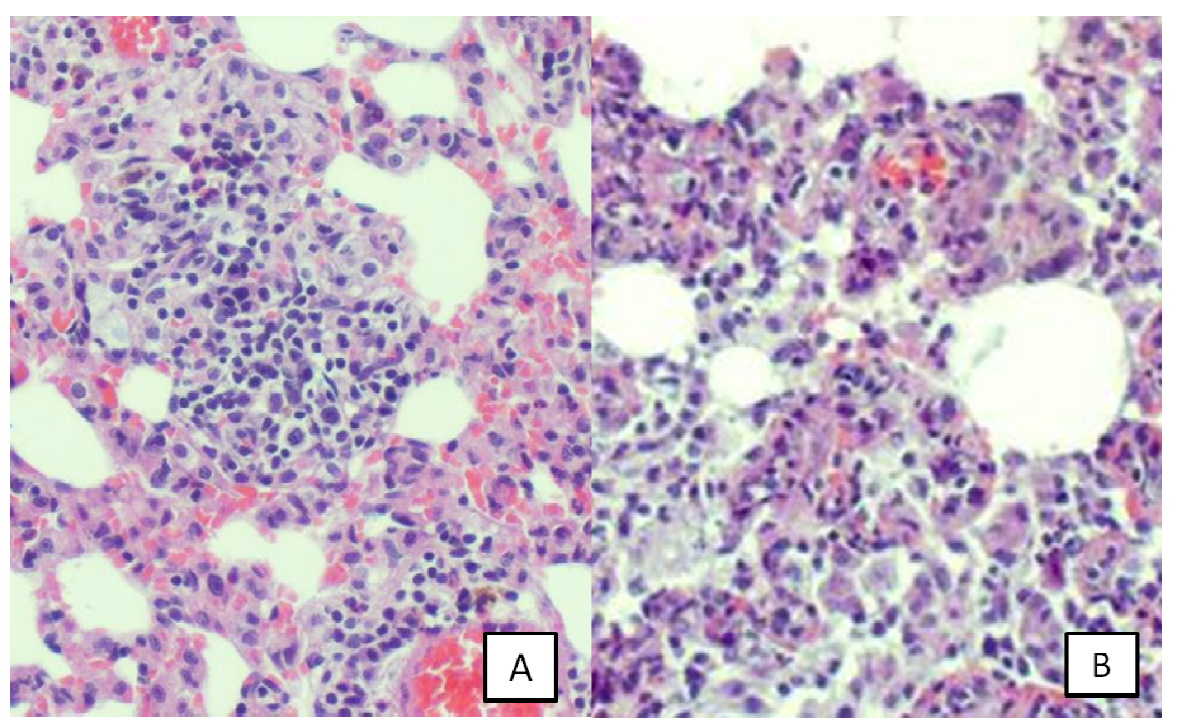

Figure 4. (A) Moderate inflammation in the lung of an erythropoietin plus methotrexate given rat $(H \& E, \times 200)$; (B) Severe inflammation in the lung of a methotrexate given rat $(H \& E, \times 200)$.

Reasons of this result may be due to be animals' low number or may be due to giving EPO in inappropriate dose or duration.

In order to protect a tissue, the required serum concentration of EPO is higher than that for erythropoiesis. Preclinical data suggest that, the minimum therapeutic level needed for tissue protection against injury appears to be 300 to $500 \mathrm{lU} / \mathrm{kg}$ body weight for the organs to be adequately investigated. In one study at a dose of $1000 \mathrm{IU} / \mathrm{kg}$, EPO was administered and it had protective effects against acute lung injury in a rat model of acute necrotizing pancreatitis (Tascilar et al., 2007). Higher doses of EPO like $5000 \mathrm{IU} / \mathrm{kg}$ are necessary for cardioprotection and neuroprotection (Bogoyevitch, 2004). We administered EPO at a dose of $5000 \mathrm{IU} / \mathrm{kg}$ to achieve the cytoprotective effect on the lung tissue. The presence of a therapeutic window dictates specific time limitations for effectiveness of exogenous EPO as a cytoprotectant (Coleman and Brines, 2004). Therefore, we administered EPO immediately 
after the MTX administration. EPO treatment in dose of $5000 \mathrm{IU} / \mathrm{kg}$ or being given only once may be the reason for failure to determine the anti-inflammatory effect.

In conclusion, our results showed that EPO administration decreases the tissue inflammation and congestion scores, and the tissue MDA level, but these decreases were not statistically significant. Being statistically insignificant may be related to the dose and duration of administered EPO. Our study is the first and preliminary study in this area. Protective effects of EPO on MTXinduced lung injury should be investigated with different doses and durations and the net results should be presented.

\section{REFERENCES}

Bedrossian CWM (1988). Latrogenic and toxic injury. In: Dail DH, Hammer SP (eds.), Pulmonary pathology. Springer Verlag, New York. pp. 511-534.

Bogoyevitch MA (2004). An update on the cardiac effects of erythropoietin cardioprotection by erythropoietin and the lessons learnt from studies in neuroprotection. Cardiovasc. Res. 63:208-216. Calikoglu M,Tamer L, Sucu N, Coskun B, Ercan B, Gul A, Calikoglu I, Kanik A (2003). The effects of caffeic acid phenethyl ester on tissue damage in lung after hindlimb ischemia-reperfusion. Pharmacol. Res. 48:397-403.

Chikura B, Sathi N, Lane S, Dawson JK (2008). Variation of immunological response in methotrexate-induced pneumonitis. Rheumatology 47:1647-1650.

Coleman T, Brines M (2004). Science review: recombinant human erythropoietin in critical illness: a role beyond anemia. Crit. Care 8:337-341.

Cooper JA Jr, White DA, Matthay RA (1986). Drug-induced pulmonary disease. Part 1: Cytotoxic drugs. Am. Rev. Respir. Dis. 133:321-340.

Cronstein BN (1996). Molecular therapeutics. Methotrexate and its mechanism of action. Arthritis Rheum. 39:1951-1960.

Dasgupta S, Mazumder B, Ramani YR, Bhattacharyya SP, Das MK (2011). Evaluation of the role of erythropoietin and methotrexate in multiple sclerosis. Indian J. Pharmacol. 43(5):512-515.

Ergur BU, Kiray M, Pekcetin C, Bagriyanik HA, Erbil G (2008). Protective effect of erythropoietin pretreatment in testicular ischemiareperfusion injury in rats. J. Pediatr. Surg. 43:722-728.

Garipardic M, Bakan V, Davutoglu M, Sayar H, Kurutas EB (2010). Oxidative stress and protective effect of erythropoietin on methotrexate-induced esophageal damage. J. Pediatr. Hematol. Oncol. 32:108-112.

Goodman TA, Polisson RP (1994). Methotrexate: adverse reactions and major toxicities. Rheum. Dis. Clin. North. Am. 20:513-528.

Jelkmann W (2007). Erythropoietin after a century of research: younger than ever. Eur. J. Haematol. 78:183-205.

Kumral A, Gonenc S, Acikgoz O, Sonmez A, Genc K, Yilmaz O, Gokmen N, Duman N, Ozkan H (2005). Erythropoietin increases glutathione peroxidase enzyme activity and decreases lipid peroxidation levels in hypoxicischemic brain injury in neonatal rats. Biol. Neonate. 87:15-18.
Laskin JD, Black AT, Jan YH, Sinko PJ, Heindel ND, Sunil V, Heck DE, Laskin DL (2010). Oxidants and antioxidants in sulfur mustardinduced injury. Ann. NY. Acad. Sci. 1203:92-100.

Maiese K, Li F, Chong ZZ (2005). New avenues of exploration for erythropoietin. JAMA 293:90-95.

Mori S, Sawada T, Okada T, Kubota K (2008). Erythropoietin and its derivative protect the intestine from severe ischemia/reperfusion injury in the rat. Surgery 143:556-565.

Naziroglu M (2007). Molecular mechanisms of vitamin E on intracellular signaling pathways in brain. In: Goth L, editor. Reactive oxygen species and diseases. Research Signpost Press, Kerala. pp. 239256.

Ohbayashi M, Suzuki M, Yashiro Y, Fukuwaka S, Yasuda M, Kohyama $\mathrm{N}$, Kobayashi $\mathrm{Y}$, Yamamoto T (2010). Induction of pulmonary fibrosis by methotrexate treatment in mice lung in vivo and in vitro. J. Toxicol. Sci. 35:653-661.

Ohkawa H, Ohishi N, Yagi K (1979). Assay for lipid peroxides in animal tissues by thiobarbituric acid reaction. Anal. Biochem. 95:351-358.

Pesce C, Mansi C, Bogliolo G, Tobia F, Pannacciulli I (1985). Pulmonary toxicity in mice after high-dose methotrexate administration with and without leucovorin rescue. Eur. J. Cancer Clin. Oncol. 21:875-880.

Rubio IT, Cao Y, Hutchins LF, Westbrook KC, Klimberg VS (1998). Effect of glutamine on methotrexate efficacy and toxicity. Ann. Surg. 227:772-778.

Salach RH, Cash JM (1994). Methotrexate: the emerging drug of choice for serious rheumatoid arthritis. Clin. Ther. 16: 911-922.

Sasaki R, Masuda S, Nagao M (2001). Pleiotropic functions and tissuespecific expression of erythropoietin. News Physiol. Sci.16:110-113.

Sepodes B, Maio R, Pinto R, Sharples E, Oliveira P, McDonald M, Yaqoob M, Thiemermann C, Mota-Filipe H (2006). Recombinant human erythropoietin protects the liver from hepatic ischemiareperfusion injury in the rat. Transplant Int. 19:919-926.

Tascilar O, Cakmak GK, Tekin IO, Emre AU, Ucan BH, Bahadir B, Acikgoz S, Irkorucu O, Karakaya K, Balbaloglu H, Kertis G, Ankarali $\mathrm{H}$, Comert M (2007). Protective effects of erythropoietin against acute lung injury in a rat model of acute necrotizing pancreatitis. World $\mathrm{J}$. Gastroenterol. 13: 6172-6182.

Thannickal VJ, Fanburg BL (2000). Reactive oxygen species in cell signaling. Am J Physiol Lung Cell Mol. Physiol.279:1005-1028.

Vogel J, Gassmann M (2011). Erythropoietic and non-erythropoietic functions of erythropoietin in mouse models. J. Physiol. 589:12591264.

Wu H, Ren B, Zhu J, Dong G, Xu B, Wang C, Zheng X, Jing H (2006). Pretreatment with recombined human erythropoietin attenuates ischemia-reperfusion-induced lung injury in rats. Eur. J. Cardiothorac. Surg. 29:902-907.

Yildirim E, Ozisik K, Solaroglu I, Kaptanoglu E, Beskonakli E, Sargon MF, Kilinc K, Sakinci U (2005). Protective effect of erythropoietin on type II pneumocyte cells after traumatic brain injury in rats. J. Trauma 58:1252-1258. 